\title{
Nonlinear FEM Simulation of Air Cushion Vehicle (ACV) Skirt Joint Under Tension Loading
}

Jia Zhou, Jinting Guo, Wenyong Tang, and Shengkun Zhang

\begin{abstract}
The mechanical properties of an air cushion vehicle (ACV) skirt cloth, which is a nonlinear rubbercoated fabric, are tested on a Series IX 4465 electron tension machine manufactured by Instron Company. Compared with the Mooney-Rivlin and Ogden form, the second-order Mooney-Rivlin form agrees with the model test result better. The ultimate bearing capacity of an ACV skirt joint structure is tested on a mechanical tension machine and the ultimate load is recorded manually. Then, considering the contact effect of each assembly and the large-displacement of skirt elements, a nonlinear finite element method (FEM)-based simulation process of an ACV skirt joint structure under tension loading is presented. The simulation process comprises three steps: assembly of parts, bolts' tightening, and tensioning the skirt cloth. Under these loadings, the stress distribution and deformation of the skirt cloth, and the cloth broken locations and directions are obtained. These results agree well with the test results. As for the ultimate bearing capacity of the skirt joint, the simulation result is slightly smaller than the test result. Thus, this FEM-based simulation method is proven to be reliable and relatively conservative.
\end{abstract}

\section{Introduction}

In the development history of an air cushion vehicle (ACV), the invention of the flexible skirt brought this amphibious craft from the laboratory investigation into a real-world application. The dream of using the air cushion as a transport platform came true. The air bag and skirt system works as the kernel part between the rigid craft body and the rough running terrain. It increases the distance between the craft and the terrain while saving a great cost of lifting power in the early state of ACV development. The flexible equipment allows the ACV to be amphibious and tolerant to an unfriendly environment, while in the ACV operation, the poor endurance of the skirt cloth is always a critical issue. It not only increases the expense of the ACV operation but also limits its popularity in the modern transportation industry. This shortage also restricts the usage of ACV under formidable natural conditions such as the polar regions. Because of these issues, the skirt research is very important and crucial for further application and generalization of the ACV.

Ma and Sullivan (1986) developed the numerical theory of the nonlinear heave dynamics of a flexible skirt and introduced the flexible bagfinger system dynamic analysis. Chung et al. (1999) applied this theory to analyze the flexible skirt system on a large amphibious ACV and compared it with the experimental results. Some optimized design was proposed based on his research. Lavis and Forstell (2005) introduced the computer-aided design method application in the skirt design. This advanced design technique effectively decreases the stress concentration on the finger surfaces of the skirt and hence extends 
Figure 1: Test Samples

Figure 2: Uniaxial Tension Test

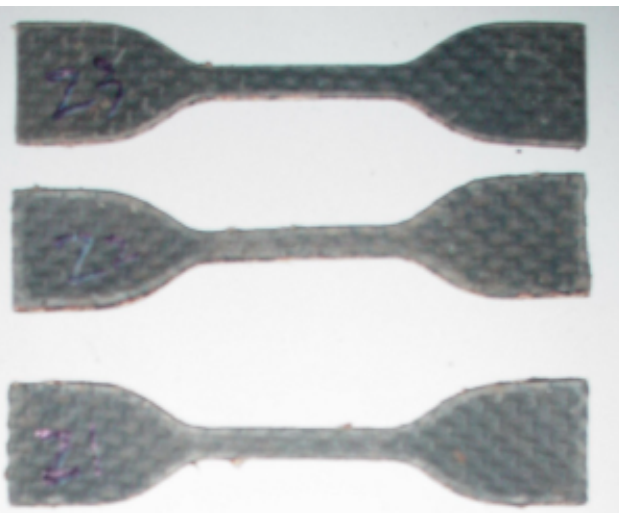

the life of the skirt. Then several research works have been performed using ABAQUS introduced by Chu and Thomas (2007), Malm et al. (2007), Zheng and Fish (2008), which is well known for its nonlinear simulation capability and user soft expansibility.

In this paper, the mechanical properties of the skirt cloth were tested. According to the test data, the analysis model was chosen and model parameters were fitted. Then, a nonlinear finite element method (FEM)-based simulation of an ACV skirt joint under dynamic loading was developed using ABAQUS. The joint consists of

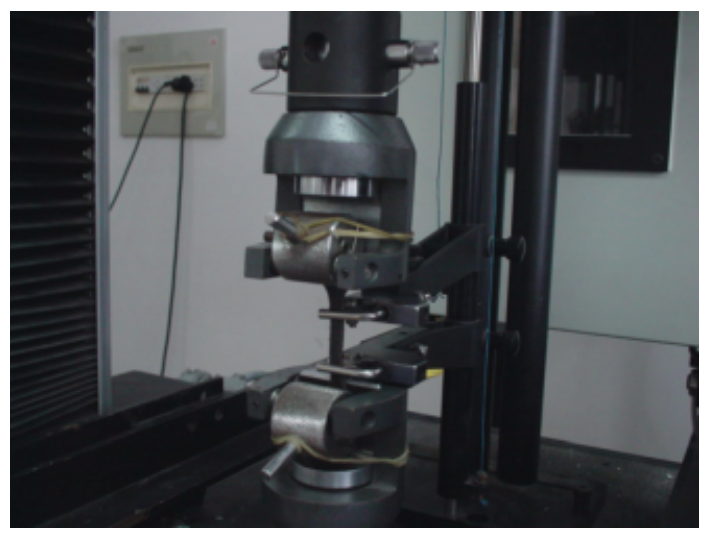

two pieces of skirt cloth screwing up by bolts. Considering the contact effects, the screw-tightening process and the cloth tension process were simulated. During these two processes, the stress distribution and deformation of the joint were achieved. The skirt cloth broken location and direction was simulated. Compared with the experimental results, the simulation is shown to be reliable. This simulation is believed to have potential in future design process applications as a substitute for the structure experiment to reduce the time and cut the cost.

\section{HCV Skirt Tests ACV SKIRT CLOTH MECHANICAL PROPERTIES' TEST}

The skirt cloth is made out of rubber-coated fabric, which consists of three constituents: rubber covering, woven fabric reinforcement, and tie-coat, which bonds the rubber and fabric together. During the manufacture, the nylon fabric is always prestretched in one direction, which is called the woven lengthwise. Followed from the application experience, the cloth always stressed in its lengthwise, which is the direction of the fabric prestretched. Hence, the samples are taken in cloth woven lengthwise, as the standard

GB/T528-1998 I model (Figure 1). The uniaxial tension test is performed on the Series IX 4465 electron tension machine made by Instron. (Instron Industrial Products, Grove City, Pennsylvania). The tension speed is $500 \mathrm{~mm} / \mathrm{min}$ (Figure 2).

The test data are shown in Table 1. Considering the aberration in the test, the maximum and minimum value $(Z 1$ and $Z 4)$ are ignored. The remaining three sample test data are fitted and the arithmetical means of the fitting results are taken as the material properties of the skirt cloth in the simulation.

\section{TABLE 1: Skirt Uniaxial Test Mechanical Properties}

\begin{tabular}{lcccc}
$\begin{array}{l}\text { Sample } \\
\text { Number }\end{array}$ & $\begin{array}{c}\text { Thickness } \\
(\mathbf{m m})\end{array}$ & $\begin{array}{c}\text { Intensity of Unit } \\
\text { Length (kN/m) }\end{array}$ & $\begin{array}{c}\text { Tensile Strength } \\
\text { (MPa) }\end{array}$ & $\begin{array}{c}\text { Elongation at } \\
\text { Break (\%) }\end{array}$ \\
\hline Z1 & 2.87 & 199.30 & 69.31 & 24.50 \\
\hline$Z 2$ & 2.87 & 167.00 & 58.24 & 22.30 \\
\hline$Z 3$ & 2.85 & 156.65 & 54.96 & 33.69 \\
\hline Z4 & 2.85 & 96.20 & 51.03 & 35.11 \\
\hline$Z 5$ & 2.83 & 144.40 & & 24.99 \\
\hline
\end{tabular}




\section{ACV SKIRT CLOTH JOINT STRUCTURE TENSION TEST}

To obtain the ultimate bearing capacity of the skirt joint structure, a tension test was performed on a tension machine, shown in Figure 3. The skirt joint sample consists of two pieces of skirt clothes connected by five sets of bolt groups with a $100 \mathrm{~mm}$ spacing. The tension loading was gradually increased. When the load reached $11.38 \mathrm{kN}$, there was a fluctuation in the loading display instrument, indicating structure failure. The broken skirt samples are shown in Figure 4. The upper skirt is shown on the upper part of the picture. It is obvious that the cracks appear at the bolt holes on the cloth and this will cause the failure of the skirt joint structure. Considering the uniform loading on each bolt group, we found that the ultimate bearing capacity of each joint is approximately $2,276 \mathrm{~N}$.

\section{JOINT NONLINEAR FEM-BASED SIMULATION UNDER DYNAMIC LOADING}

In this section, the FEM calculation was performed to simulate the joint structure tension test with the material properties acquired in the previous section. Considering the symmetry of the joint structure and the efficiency of the analysis, only one set of the bolts and the connected skirt are modeled.

\section{PRINCIPAL DIMENSIONS}

Skirt cloth: $120 \mathrm{~mm} \times 100 \mathrm{~mm} \times 2.8 \mathrm{~mm}$ (length $\times$ breadth $\times$ thickness) with a $10 \mathrm{~mm}$ diameter hole at the center;

Screw: Screw cap: $40 \mathrm{~mm}$ outer diameter and $32 \mathrm{~mm}$ inner diameter, $6 \mathrm{~mm}$ height; Screw column: $8 \mathrm{~mm}$ diameter, $23.7 \mathrm{~mm}$ height; Bolt: $40 \mathrm{~mm}$ diameter with an $8 \mathrm{~mm}$ inner diameter.

\section{FEM MODEL}

Considering the balance of simulation reality and the calculation efficiency, the mesh properties of each component are as shown in Table 2.

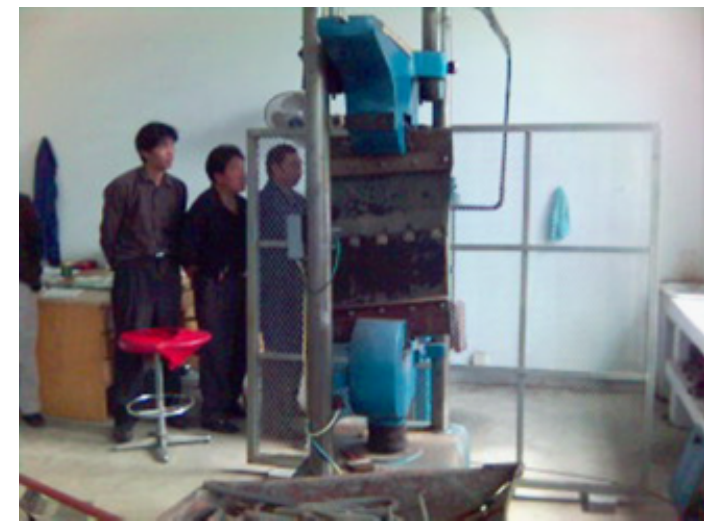

Figure 3: Skirt Connect Joint Tension Test

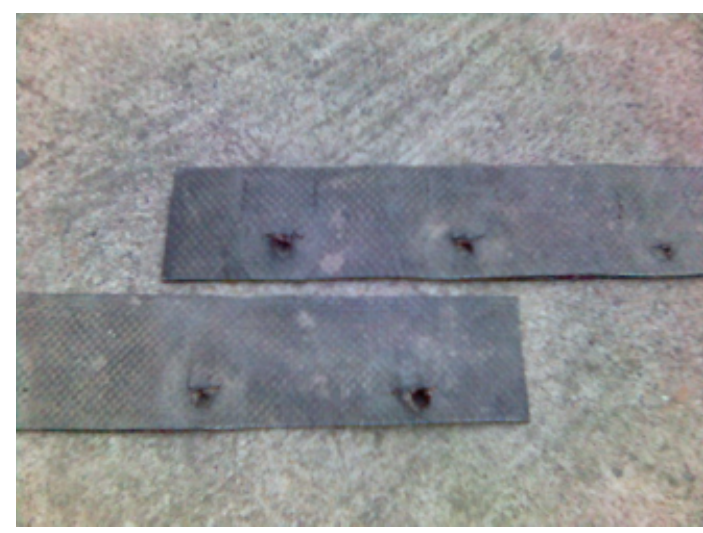

Figure 4: Samples after a Tension Test

\section{MATERIAL PROPERTIES}

The screw and the bolt are both defined as steel. Hence, the density is $7.8 \times 10^{-6} \mathrm{t} / \mathrm{mm}^{3}$, Young's modulus of elasticity is $2.1 \times 10^{5}$, and Poisson's ratio is 0.3 .

The skirt cloth is made out of a rubber-coated fabric and the mechanical properties were determined from the uniaxial test, which was

\begin{tabular}{lccc}
\multicolumn{3}{l}{ TABLE 2: } & Mesh Properties of Each Part \\
\hline Part & Nodes & Elements & Element type \\
\hline Skirt & 834 & 504 & Hexahedral element \\
\hline Bolt & 268 & 742 & Tetrahedral element \\
\hline Screw & 190 & 76 & Hexahedral element
\end{tabular}

TABLE 3: Fitting Constant for the Second-Order Polynomial Mooney-Rivlin Form

\begin{tabular}{lcccccc} 
D1 & C10 & C01 & D2 & C20 & C11 & C02 \\
\hline 0.00 & -853.61 & 903.83 & 0.00 & $27,377.70$ & $-65,752.32$ & $40,373.39$
\end{tabular}


Figure 5: Constant Fitting of MooneyRivlin Form

\section{Figure 6: Constant} Fitting of Ogden Form

Figure 7: Parts' Assembly Side View
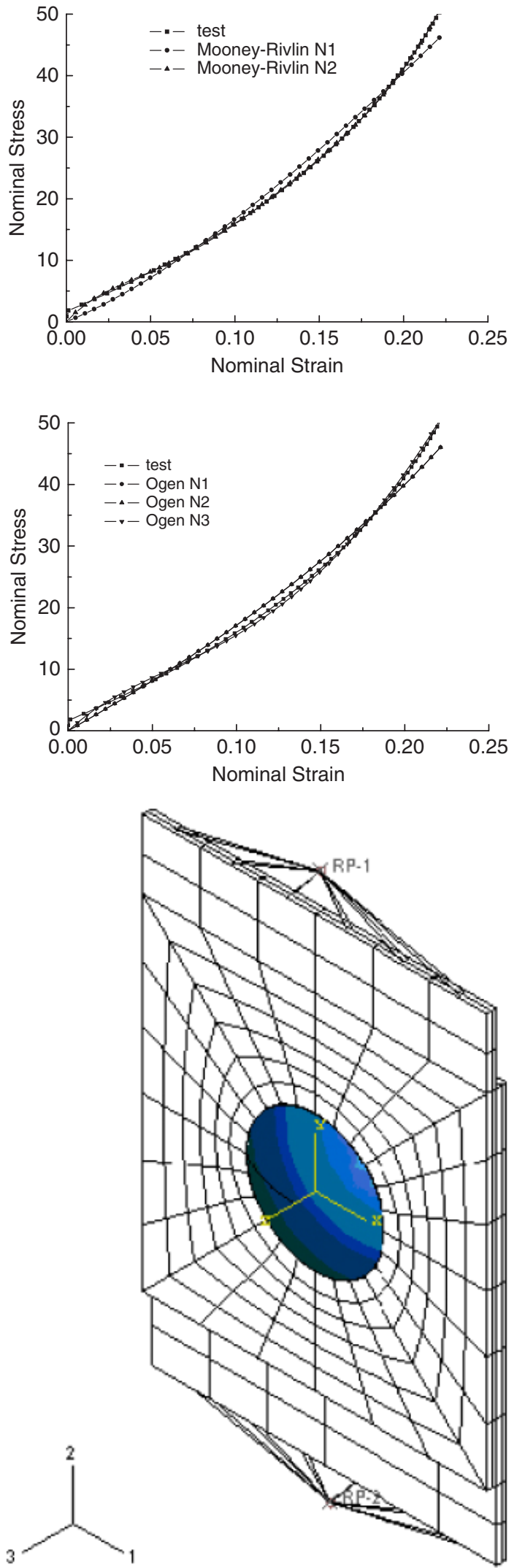

discussed under "ACV Skirt Tests." Before simulation, the material of the model should be chosen. There are two commonly used rubber models: Mooney-Rivlin form (Rivlin and Saunders 1951) and Ogden form (Ogden 1984). By fitting the form constant, the results are given in Figures 5 and $\mathbf{6}$. It is clear that the second-order polynomial Mooney-Rivlin form agrees better with the model test data compared with the other options. Hence, this form was chosen to be applied in the simulation. The form constants are given in Table 3.

\section{PARTS' ASSEMBLY AND CONTACT DEFINITION}

The pieces of the cloth have a hole at the center and are screwed up by the bolt. Before simulating the dynamic loading process, the parts should be assembled and the location should be defined. As shown in Figures $\mathbf{7}$ and $\mathbf{8}$, from the top of the structure to the bottom, there is a $0.1 \mathrm{~mm}$ gap between the screw cap and the top skirt cloth. Then two pieces of cloth and the bolt are in direct contact. The screw and the bolt are cocentered with the hole of both skirts. All the contact pairs are defined as a penalty function; the friction factor is taken as 0.2 .

\section{SIMULATION OF A SKIRT JOINT UNDER DYNAMIC LOADING}

The dynamic loading contains two steps. The first step is the screw-tightening process. Then, maintaining the tightening stress, the second step is stretching the skirt cloth with increasing tension until the skirt cloth is broken. While simulating the skirt cloth load bearing, the stress distribution and structure deformation of the cloth is observed. All the loads are smoothed by second-order continuity, avoiding the simulation distortion caused by a sudden change of the boundary conditions. In both steps, the

\section{TABLE 4: Tightening Force Loading Definition}

$\begin{array}{llllll}\text { Time (s) } & 0 & 0.01 & 0.02 & 0.03 & 0.04 \\ \text { Displacement }(\mathrm{mm}) & 0 & 0.1 & 0.1 & 0.2 & 0.2\end{array}$


large displacements of skirt cloth elements were considered.

\section{Screw Tightening}

Boundary Conditions-Two fringes of the skirt cloth (in Figure 7 the top fringe of the top skirt and the down fringe of the bottom skirt) and the bottom side of bolt are fixed.

Load Definition-The tightening load is loading on the screw cap with the displacement form and the loading process is given in

Table 4.

Simulation Results-After the tightening stress was loaded, the stress distribution of the skirt cloth is as shown in Figures $\mathbf{9}$ and $\mathbf{1 0 .}$ It can be seen that the stress of the top skirt is greater than that of the bottom one with the screw-tightening effect. The maximum stress appears at the region in the vertical column of the screw cap, on the contact surface of two pieces of the skirt cloth. In this region, the contact restriction limits the deformation of the cloth, and so a high stress concentration appears. This phenomenon matches the real application. Then, considering the structure's internal energy and kinetic energy, the energy grew in a stable manner with no drastic fluctuation. Thus, this simulation of the tightening process is credible.

\section{Skirt Tension}

Boundary Conditions-In this step, the boundary condition of the bolt remains the same as the previous simulation step. Then the fixed boundary of the skirt cloth is replaced.

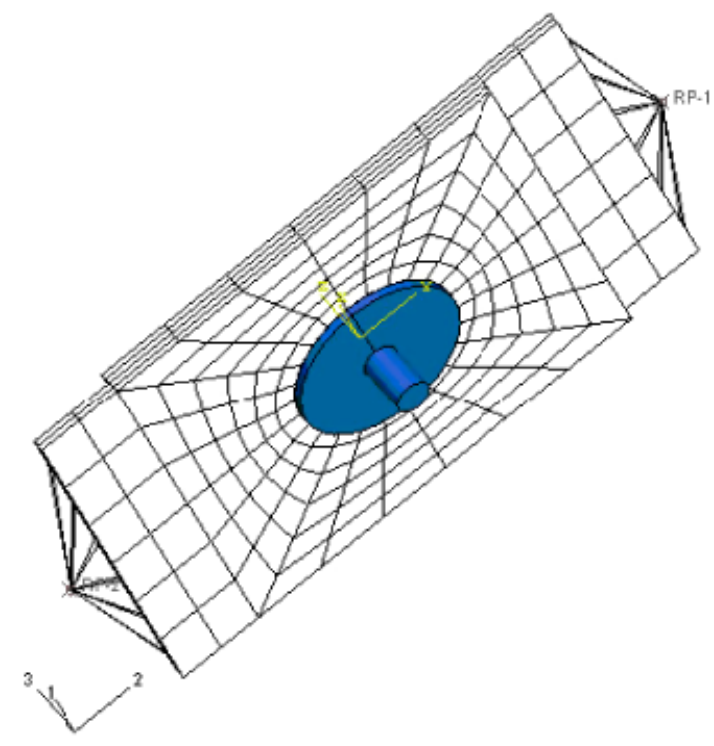

Figure 8: Parts' Assembly Bottom View

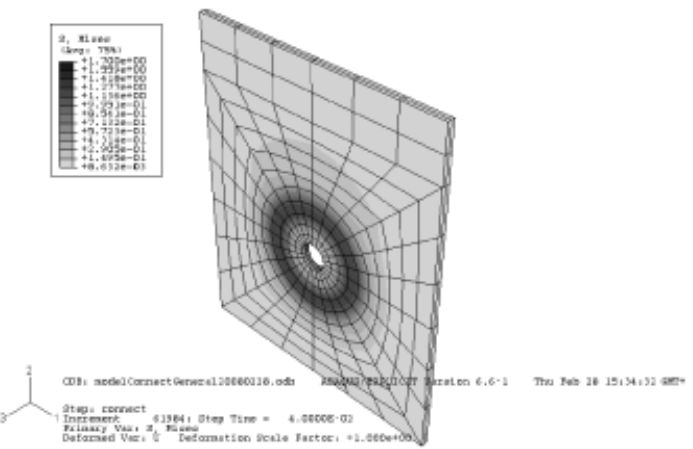

Load Definition-As shown in Figure 5, two reference points are set in both sides of the skirt fringe, which is fixed in the previous step, and tied to the cloth surface. The tension force

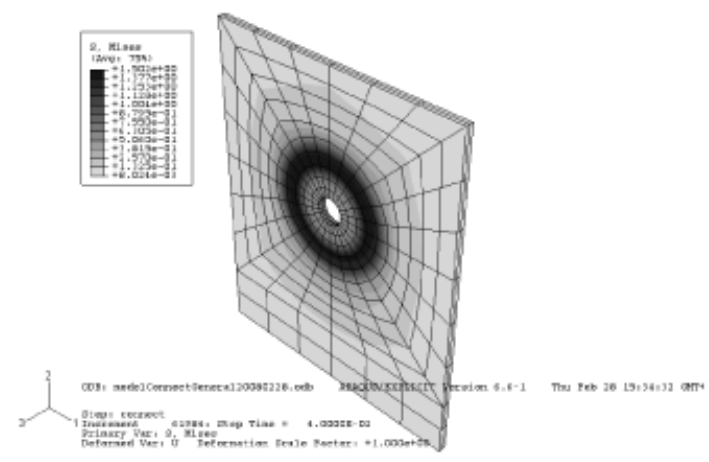
Distribution of the Upper Skirt after Being Tightened
Figure 9: Stress
Figure 10: Stress Distribution of the Lower Skirt after Being Tightened

\section{TABLE 5: Tension Force Loading Definition}

\begin{tabular}{|c|c|c|c|c|c|c|c|c|c|c|c|c|}
\hline Time (s) & 0 & 0.01 & 0.1 & 0.2 & 0.3 & 0.4 & 0.5 & 0.6 & 0.7 & 0.8 & 0.9 & 1 \\
\hline Tension (N) & 0 & 10 & 100 & 500 & 800 & 1,000 & 1,200 & 1,400 & 1,600 & 1,800 & 2,000 & 2,200 \\
\hline
\end{tabular}


Figure 11: Stress Distribution of the Upper Skirt before Tension Is Broken

Figure 12: Stress Distribution of the Lower Skirt before Tension Is Broken

Figure 13: Tension Broken Location and Direction of the Upper Skirt

Figure 14: Tension Broken Location and Direction of the Lower Skirt

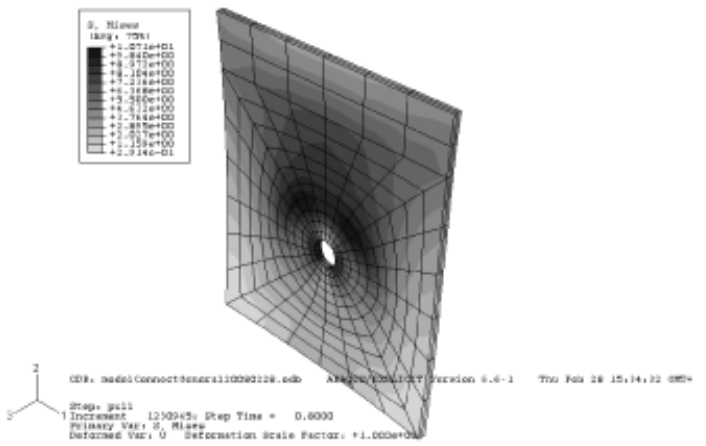

Simulation Results-Before reaching the ultimate strength limit, the stress distributions of the cloth are given in Figures $\mathbf{1 1}$ and $\mathbf{1 2}$. As shown in Figures 11 and 12, because of the tension load, the skirt cloth has a large degree of deflection. The hole, at the center of the skirt, is remarkably elongated. The stress distribution of the cloth is an order greater than those in the previous process (Figures 9 and 10). Because of the contact effect of the screw cap and the bolt, the stress concentration appears near the open hole at the tension side of the cloth. The stress levels of each cloth are similar on both upper and lower surfaces.

Figures 13 and 14 show the cloth broken locations and directions. Under the load defined above, the maximum stress of the skirt cloth grew rapidly to nearly second order when the simulation started at about $0.8 \mathrm{~s}$, and there emerged a peak value in the structure's kinetic energy. Hence, the skirt cloth is considered applied on the reference point can be evenly distributed on the cloth. The loading steps are given in Table 5. faulty and the critical tension is about $1,880 \mathrm{~N}$. The directions of the principal stress are shown by the arrows. Compared with the joint tension test results, the simulated point that experienced the highest stress load is the same and the critical load is $396 \mathrm{~N}$ smaller, which is about $17 \%$ less than the test result. Thus, the simulation results are relatively conservative but reliable.

\section{Conclusions and Suggestions}

A nonlinear FEM-based simulation of an ACV skirt joint structure under dynamic loading is presented. Firstly, the mechanical properties of skirt cloth that is made out of a nonlinear rubber-coated fabric, are tested on a Series IX 4465 electron tension machine made by Instron Company. Then comparing different orders of the Mooney-Rivlin form and the Ogden form, the second-order Mooney-Rivlin form is applied to the simulation. This conclusion can be used in future simulation work. In the simulation process, the contact effects are considered and the friction coefficient is defined. The simulation comprises two loading steps and the previous loads are propagated in the second simulation step. The simulation results agree with the 
structure test results. Although the ultimate capacity of the skirt cloth is slightly

underestimated, this simulation method is still considered to be reliable.

Because the manufacturing technique of skirt cloth is not well developed, the mechanical properties of the skirt cloth may vary, depending on the manufacturer. The accurate material properties need to be tested more specifically in future research. On the other hand, there is only one friction coefficient defined in the simulation model. As the contact properties of screw, skirt cloth, and bolt are different, and they also depend on the environment conditions of $\mathrm{ACV}$, further research is required.

\section{References}

ABAQUS Version 6.6 Documentation [M]. SIMULIA, Providence, Rhode Island. Information available at www.simulia.com.

Chu, X.T. and N. Thomas, "Experimental and numerical modeling of interfacial behavior between galvanised steel and aerated concrete," International Journal of Modeling, Identification and Control, Vol. 2, No. 3, pp. 208-218, 2007.

Chung, J., P.A. Sullivan, and T. Ma, "Nonlinear heave dynamics of an air cushion vehicle baģ and finger skirt," Journal of Ship Research, Vol. 43, No. 2, pp. 79-94, 1999.

Lavis, D.R. and B.G. Forstell, Air cushion vehicle (ACV) development in the US, FAST2005. St. Petersburg, Russia, 2005.

Ma, T. and P.A. Sullivan, "Linear analysis of the heave dynamics of a bag and finger air cushion vehicle skirt." AIAA 8th Advanced Marine Systems Conference, 1986, USA, AIAA.
Malm, C.G., W.G. Davids, M.L. Peterson, and H. Zhang, "Finite element analysis of woven airbeams." ASME International Mechanical Enģineering Congress and Exposition October 5-10, 2007: 649-652.

Ogden, R.W., Non-linear elastic deformations, Ellis Horwood, Chichester, 1984.

Rivlin, R.S. and D.W. Saunders, "Large elastic deformations of isotropie materials: VII experiments on the deformation of rubber [J]," Philosophical Transactions of the Royal Society of London, Vol. A243, pp. 251-288, 1951.

Zheng, Y. and J. Fish, "Toward realization of computational homogenization in practice," International Journal for Numerical Methods in Engineering, Vol. 73, No. 3, pp. 361-380, 2008.

\section{Huthor Biographies}

Jia Zhou, Ph.D. School of Naval Architecture, Ocean and Civil Engineering, Shanghai Jiao Tong University, Shanghai, China; Offshore Engineering \& Work Boat Design Division, MARIC-Marine Design \& Research Institute of China, Shanghai, China.

Jinting Guo is a Ph.D. candidate in the Naval Architecture and Marine Engineering Department at the University of Michigan, Ann Arbor, MI.

Wenyong Tang is Professor and Ph.D. Director, School of Naval Architecture, Ocean and Civil Engineering, Shanghai Jiao Tong University, Dongchuan Road 800, Shanghai 200240, China. Professor Tang is the corresponding author for this article.

Shengkun Zhang is Professor, Ph.D. Director, School of Naval Architecture, Ocean and Civil Engineering, Shanghai Jiao Tong University, Shanghai, China. 